\title{
CONHECIMENTO CIENTÍFICO SOBRE COMÉRCIO JUSTO: UM ESTUDO BIBLIOMÉTRICO DE 2001 A 2013
}

\author{
Letícia Santos Franca \\ Graduada em Administração pela PUC Rio (IAG/PUC-Rio) \\ leticiafranca89@yahoo.com.br \\ Lucas Martins Turano \\ Mestre em Administração pela PUC Rio (IAG/PUC-Rio) \\ lucas.turano2@gmail.com \\ Andrea Cherman \\ Doutora em Administração de Empresas pela PUC Rio (IAG/PUC-Rio) \\ Professora do Departamento de Administração da PUC-Rio. \\ a.cherman@globo.com
}

\section{RESUMO}

Este estudo visa identificar os corpos teóricos dominantes nas pesquisas internacionais sobre o tema Comércio Justo. Apesar de ser ainda um campo de estudo relativamente recente, ele já possui uma grande quantidade de informações. Sabendo disso, buscou-se, por meio desse trabalho, analisar todas as publicações sobre o tema, de janeiro de 2001 a dezembro de 2013, indexadas na base Web of Science. Metodologicamente, adotou-se um estudo bibliométrico, analisando principalmente citações e cocitações, que encontrou, no total, 235 artigos publicados no período. Como principal resultado, este trabalho culminou na descoberta, a partir da construção de um mapa, de uma nova forma de estruturação e categorização das pesquisas sobre esse tema. Além disso, foi identificada, nos trabalhos analisados, que a principal lacuna encontra-se no estabelecimento de estratégias para operacionalização do tema, que se apoia, sobretudo, na dificuldade de aderência por parte do consumidor em exercer uma atitude positiva na compra de um produto de Comércio Justo. Nesse sentido, os achados demonstram que o campo de pesquisas sobre Comércio Justo deve ser incentivado, enaltecendo-se a necessidade de se desenvolver rapidamente estratégias mais consolidadas. Com base nos resultados, esta pesquisa sugere algumas implicações não só teóricas, mas, sobretudo, práticas para o desenvolvimento da área.

Palavras-chave: Bibliometria; Consumerismo ético; Consumo sustentável; Comércio justo; Estratégia social e ambiental.

\section{SCIENTIFIC KNOWLEDGE ON FAIR TRADE: A BIBLIOMETRIC STUDY FROM 2001 TO 2013}

\begin{abstract}
This study aims to identify the dominant theoretical approaches in international research on the Fair Trade topic. Although it is still a relatively new field of study, Fair Trade already counts with a big amount of information. The present study sought to examine all publications on the subject, from January 2001 to December 2013, indexed in the Web of Science database. Methodologically, we adopted a bibliometric study, mainly analyzing citations and co-citations; we found a total of 235 articles published in the period. The main result culminated in the discovery, illustrated in a map, of a new way of structuring the subject of research. Furthermore, we identified that the main research gap would be to establish strategies for operationalization of the theme, which is based mainly on the consumers' distress to exercise a positive attitude in purchasing a Fair Trade product. In this sense, the findings show, overall, that the Fair Trade field should be a search target for researchers, highlighting the need to quickly develop more consolidated strategies. Based on these ideas, we suggest some theoretical and practical implications in order to develop this field of study.
\end{abstract}

Key words: Bibliometrics; Ethical consumerism; Fair trade; Social and environmental strategy; Sustainable consumption. 


\section{INTRODUÇÃO}

O movimento do Comércio Justo se caracteriza como um esforço para criar padrões de produção e consumo alternativos para os padrões destrutivos, social e ambientalmente desiguais, inerentes à produção e ao comércio de sistemas tradicionais (Murray; Raynolds, 2000). Assim, o Comércio Justo é uma relação de troca justa entre todos os elos da cadeia produtiva, baseada no diálogo, na transparência e no respeito, que busca maior igualdade no comércio internacional (Fine, 2005).

Neste processo, o consumidor é uma peça fundamental, uma vez que é por meio dele que se concretiza o ciclo da cadeia produtiva de comércio justo. Entretanto, existem estudos (e.g. Pelsmacker et al., 2005) que mostram que o comportamento de compra dos consumidores não é coerente com a sua atitude positiva para produtos éticos, como, por exemplo, produtos de Comércio Justo. Nicholls (2002), por sua vez, aponta que uma estratégia junto ao consumidor necessita de uma consideração mais ampla, uma vez que está em processo de construção. Ademais, uma estratégia voltada para o consumidor torna coerente sua atitude positiva para a compra de um produto de Comércio Justo.

O Comércio Justo, como segmento econômico mensurável, ainda é um movimento relativamente jovem. Apesar disso, a quantidade de dados encontrados sobre o assunto e temas correlatos no cenário internacional é bastante grande (Sebrae, 2007). Tendo isso em mente, torna-se necessário visualizá-los e organizá-los para melhor compreensão e aprofundamento sobre esse tema. Diante disso, surgem as seguintes perguntas de pesquisa: quais são os corpos teóricos dominantes nas pesquisas internacionais sobre Comércio Justo? Qual o panorama atual do Comércio Justo de acordo com dados de investigações realizadas até o momento? Visando responder a estas perguntas, foram analisadas todas as publicações sobre o tema, de janeiro de 2001 a dezembro de 2013, indexadas na base Web of Science.

Metodologicamente, adotou-se um estudo bibliométrico de citações e cocitações, cujo escopo quantitativo revelou o total de 235 artigos publicados no período. Com o objetivo de identificar quais são os corpos teóricos dominantes, entender a relação existente entre estes e como está o panorama atual do Comércio Justo, este trabalho elaborou um mapa de cocitações que culminou na descoberta de uma nova forma de estruturação da pesquisa acerca do tema, identificando um ponto crucial para o sucesso do Comércio Justo na prática.

\section{REFERENCIAL TEÓRICO}

O movimento de Comércio Justo surgiu na Europa no final do século XIX, entre as décadas de 1960 e 1970, como uma forma de difundir, apresentar e divulgar uma alternativa de comércio, tendo em vista as injustiças e os desequilíbrios sociais causados pelo comércio internacional (Asti, 2007; Brasil Social Chic, 2014). Nesse sentido, Moore (2004) ressalta em seu estudo que a construção do conceito de comércio justo teve seu início em 1940, com as negociações entre Mennonite Central Committee com as comunidades pobres do Sul (Ifat, 2003), mas apenas a partir de 1960 e 1970 que começou a ser reconhecido como um movimento e, assim, expandiu-se pela Europa.

Esse movimento tem crescido significativamente desde aquela época, mas ainda continua a ser relativamente pequeno em termos de negócios no mercado. Entretanto, tem atraído a atenção na literatura acadêmica a partir de uma ampla gama de disciplinas, tais como economia, marketing, design, agricultura, estudos de desenvolvimento e teologia. No entanto, a exposição, no âmbito da literatura de negócios e gestão em geral e da literatura éticas de negócio em particular, tem sido limitada (Moore, 2004).

O conceito de Comércio Justo não possui uma única definição estabelecida por uma entidade internacional. Contudo, as diferentes conceituações existentes se coadunam de forma a tentar definir 
melhor o seu conceito de acordo com as diferentes entidades internacionais. Para esse estudo, serão utilizadas as duas definições mais reconhecidas, que são: 1) Fine, uma conjunção das iniciais das quatro principais entidades do Comércio Justo - Flo, Ifat, News! e Efta; e 2) World Fair Trade Organization (Wfto), única organização que representa todos os aspectos do comércio equitativo dos produtores para os vendedores e que opera em 70 países (Faces do Brasil, 2014; Crossing Borders Fair Trade, 2014).

Definição segundo a Fine (2005):

O Comércio Justo é uma relação de troca, baseada no diálogo, na transparência e no respeito, que busca maior igualdade no comércio internacional. Contribui ao desenvolvimento sustentável oferecendo melhores condições comerciais; assegurando o direito dos pequenos produtores e trabalhadores marginalizados, especialmente do Sul. Organizações de Comércio Justo estão envolvidas ativamente em apoiar produtores, divulgar o comércio justo e em campanhas para modificar as regras e as práticas do mercado convencional internacional.

Definição da Wfto (2014):

O Comércio Justo é uma parceria comercial baseada no diálogo, na transparência e no respeito, que busca maior equidade no comércio internacional. Contribui para o desenvolvimento sustentável, oferecendo melhores condições comerciais, e garantir os direitos dos produtores e trabalhadores marginalizados - especialmente no sul. Organizações de Comércio Justo, apoiadas pelos consumidores, estão envolvidas ativamente no apoio aos produtores, na sensibilização e nas campanhas para mudanças nas regras e práticas do comércio internacional convencional.

A Wfto define os 10 princípios de Comércio Justo que as organizações, empresas e/ou cooperativas devem seguir no cotidiano do seu trabalho. Além disso, a Wfto também realiza um acompanhamento para garantir que estes princípios sejam respeitados por todos os elos da cadeia produtiva (Wfto, 2014):

1. Criar oportunidades para produtores economicamente em desvantagem

2. Manter transparência e responsabilidade

3. Construir capacidades dos produtores

4. Promover o Comércio Justo.

5. Pagar um preço justo em todos os elos da cadeia

6. Respeitar a igualdade de gêneros

7. Manter um ambiente de trabalho saudável e seguro

8. Não permitir trabalho infantil

9. Respeitar o meio ambiente

10. As relações comerciais devem visar o bem-estar dos produtores e não a maximização de lucros.

Para as organizações, empresas e/ou cooperativas divulgarem que praticam Comércio Justo para seus consumidores e clientes, elas devem passar pelo processo de implementação e certificação e, assim, se tornar um membro da Wfto (International Fair Trade Association, 2010).

\subsection{Da implementação à certificação de comércio justo}

Todos os produtos de Comércio Justo são originários de produtores e trabalhadores comprometidos com os 10 princípios de Comércio Justo. No entanto, os produtos de Comércio Justo são negociados e comercializados por meio de dois canais distintos, mas complementares: os elos da cadeia de suprimentos integrada, em que os produtos são importados e/ou distribuídos por 
organizações que têm Comércio Justo no núcleo da sua missão e atividades; e a rota de certificação do produto, que deve estar em conformidade com as normas internacionais de certificação, indicando que ele foi produzido, comercializado, processado e embalado de acordo com as necessidades específicas dessas normas internacionais (Wfto, 2014).

O Sebrae (2007) elaborou uma Pesquisa Mundial de Comércio Justo que define um modelo de processo da cadeia de Comércio Justo que apresenta todos os stakeholders envolvidos. O diagrama apresentado na figura 1 mostra como funciona o sistema de Comércio Justo e indica quais são as funções de uma Iniciativa Nacional.

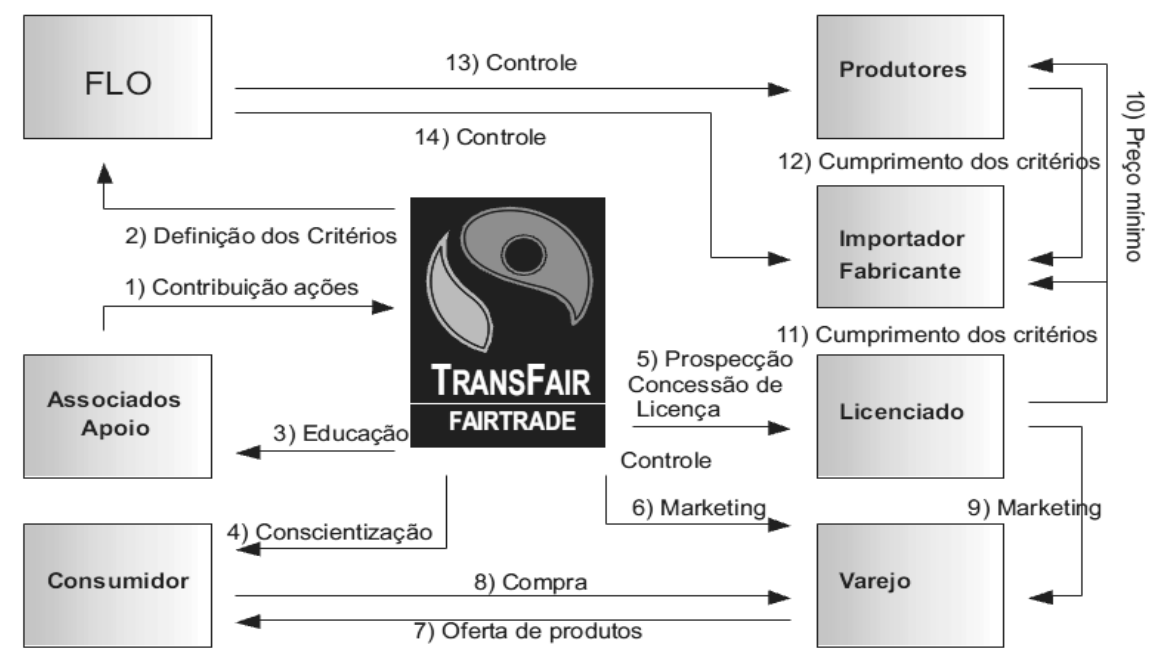

Figura 1 - O sistema de comércio justo

Fonte: (Sebrae, 2007)

No centro de todo sistema estão as iniciativas nacionais, que assumem a principal parte dos trabalhos. (1) Recebem recursos e apoio de seus associados; (2) ajudam a definir os critérios internacionais de certificação de produtos e produtores junto com a $F L O$; (3) realizam ações e campanhas de educação de seus associados; (4) atuam na conscientização do público consumidor, além desenvolver ações de lobby junto a órgãos governamentais; (5) prospectam licenciados para a fabricação de produtos, para os quais são concedidas as licenças de uso do selo de Fair trade e que receberão o controle regular; (6) oferecem apoio e orientação para o marketing das lojas; (7) o lojista oferece uma gama de produtos (7) e o consumidor compra os produtos (8); O licenciado fornece apoio de marketing às lojas (9) e paga o importador que, por sua vez, paga o produtor (10). Em contrapartida, o importador e os produtores se comprometem a seguir os critérios estabelecidos (11 e 12) em suas relações. A FLO, depois de ter definido os critérios, certifica e controla os produtores e os importadores (13 e 14) (Sebrae, 2007).

As certificações e rotulagens são instrumentos para alcançar mercados promissores, que aproveitam os mecanismos próprios da globalização para enfrentar a inequidade. Iniciativa como a prática de comércio justo está sendo vista como resposta inovadora que cria uma relação ganhaganha às lutas econômicas e ambientais aparentemente insolúveis (WWF, 2001b). No entanto, um dos mais sérios desafios da certificação e rotulagem hoje é realmente para ser no mercado, mas não dele, isto é, para ser capaz de perseguir valores alternativos e objetivos, tais como a justiça social e a sustentabilidade ambiental, sem ser capturado pela lógica convencional do mercado, das práticas e dos atores dominantes (Taylor, 2005). 


\subsection{Participação do consumidor na cadeia de Comércio Justo}

O consumidor é uma peça fundamental, uma vez que é por meio dele que se concretiza o ciclo da cadeia produtiva de comércio justo. Os consumidores podem expressar a sua preocupação com o comportamento ético das empresas no ato da compra. Em geral, o consumidor ético se sente responsável para com a sociedade e expressa esses sentimentos por meio de seu comportamento de compra (Pelsmacker et al, 2005). Doane (2001) definiu o consumo ético como a compra de um produto que diz respeito a uma determinada questão ética (direitos humanos, condições de trabalho, bem-estar animal, meio ambiente, entre outras), sendo escolhida livremente por um consumidor individual. O consumidor ético é alguém com alto nível de consciência e intencionalidade. Sua ação de consumo envolve a escolha consciente de produtores e produtos, com o objetivo de mudar práticas de mercado com base em valores essencialmente não econômicos, como bem-estar pessoal e familiar, justiça e equilíbrio por meio de práticas de negócio (Micheletti, 2003). Atividade de consumo ético inclui comportamentos positivos de escolha, como a compra de produtos comercializados de forma justa, ou ambientalmente amigáveis (Cherrier, 2007; Newholm \& Shaw, 2007).

Consumidores do comércio justo podem usar o seu poder de compra no mercado para resolver os problemas sociais e ambientais do mercado global (Taylor, 2005). Entretanto, existem estudos, tal como o de Pelsmacker (2005), que mostram que o comportamento de compra dos consumidores não é coerente com a sua atitude positiva para produtos éticos. Outras explicações para a discrepância entre atitudes e comportamento de compra ética pode ser a falta de disponibilidade de produtos éticos, descrença das reivindicações éticas, e a própria falta de informação (Carrigan \& Attalla, 2001; Mielants; Pelsmacker; Janssens, 2003; Roberts, 1996).

\subsection{Estratégia em tornar prático o conceito de Comércio Justo}

Nicholls (2002) concluiu que uma estratégia junto ao consumidor necessita de uma consideração mais ampla, uma vez que está em processo de construção. O autor ainda afirma que os produtos de comércio justo no âmbito da oferta junto aos varejistas possuem uma oportunidade de desenvolver uma vantagem competitiva e melhorar a sua própria marca no mercado. No entanto, há, claramente, ainda a necessidade de uma análise mais ampla dos contextos estratégicos e operacionais do comércio justo pelos varejistas. Estes precisam ter a percepção da vantagem competitiva que um produto de Comércio Justo pode proporcionar, tanto para as vendas, quanto para a sociedade como um todo.

Strong (1997) sugere três questões chaves referentes a aparente discrepância entre a intenção de compra expressada e o comportamento de compra efetivo, a saber: (1) a forma como está sendo comunicado ao consumidor os produtos ditos éticos e sustentáveis; (2) a garantia do comprometimento de compra de produtos de comércio justo; (3) a dificuldade no posicionamento dos produtos de comércio justo nas gôndolas de supermercados. Deste modo, faz-se necessário desenvolver soluções estratégicas para essas questões. Além disso, discussões com atores-chave no desenvolvimento comercial de Comércio Justo têm enaltecido a necessidade de um modelo integrado de opções estratégicas que atue como resposta ao consumerismo ético. Nesse sentido, o trabalho de Nicholls (2002) propõe um guia para uma estratégia proativa.

\section{MÉTODO DO ESTUDO}

Este estudo busca realizar, quantitativamente, uma revisão da literatura internacional sobre o tema comércio justo. Delimitou-se como escopo somente as publicações internacionais, visto que esta produção é mais consistente, ampla e geradora de tendências do que a nacional. Para tanto, adotou-se o método bibliométrico, analisando, principalmente, citações e cocitações. Este método 
científico objetiva encontrar padrões e tendências nas pesquisas, por meio da análise de citações e cocitações (White e Mccain, 1998). Como, geralmente, trabalhos que recebem mais citações possuem uma maior relevância para o encadeamento de novos estudos, faz-se necessário observálos. Da mesma forma, uma análise de cocitações permite não só mapear trabalhos com conteúdos e teorias comuns, como, também, suas possíveis tendências. Para isso, o escopo temporal do artigo foi delimitado visando abranger o interstício de 01 de janeiro de 2001 a 31 de dezembro de 2013.

No que se refere aos procedimentos adotados, primeiramente, foi realizada uma busca pelo tema, a partir do preenchimento da palavra-chave "Fair Trade" no campo "Tópico" da base de dados Web of Science. Escolheu-se essa base pelo fato de ela ser considerada a principal base de dados para as ciências sociais aplicadas e humanas pela Coordenação de Aperfeiçoamento de Pessoal de Nível Superior (Capes, 2010). O passo seguinte foi a filtragem dos artigos por meio do software bibexcel, responsável por organizar dados e prepará-los para análises estatísticas mais robustas. As referências dos trabalhos coletados foram normalizadas manualmente, a fim de que os volumes, nomes de autores e páginas publicadas não apresentassem quaisquer inconsistências. Quando livros iguais foram citados, porém de edições diferentes, eles foram agrupados de acordo com a edição que havia recebido mais citações. Por fim, utilizou-se o software SPSS que desenvolveu o produto final da análise: o mapa de cocitações. Um resumo dos procedimentos adotados e da forma de tratamento dos dados pode ser visto abaixo, na figura 2.

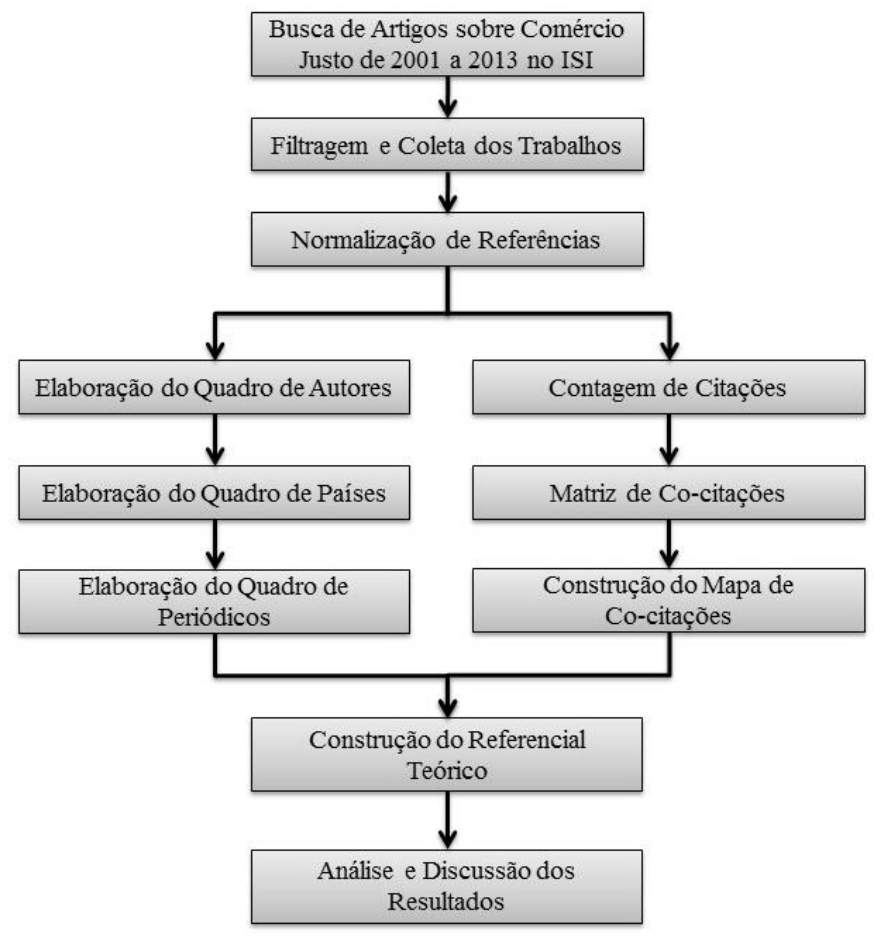

Figura 2 - Diagrama de tratamento dos dados Fonte: Elaborado pelos autores

A pesquisa detalhadamente ilustrada acima resultou no encontro de 235 artigos, no total, que foram localizados com base nos critérios estabelecidos anteriormente. Essa amostra coletada foi, então, mais profundamente analisada e seus resultados são apresentados a seguir.

\section{ANÁLISE DE RESULTADOS}

Na primeira etapa, pesquisou sobre os autores que mais publicaram sobre o tema comércio justo de 2001 a 2013 (tabela 1). Optou-se por enumerar todos os autores que obtiveram um mínimo de três publicações neste ínterim, que resultou na nomeação de 11 pesquisadores. Ademais, para 
fins de classificação, a ordem de autoria no artigo não foi considerada, sendo contabilizados todos os trabalhos em que os autores haviam contribuído. O primeiro lugar no ranking foi ocupado por Becchetti, filiado à universidade italiana Tor Vergata, com um total de oito publicações, representando $3,4 \%$ de todas as 235 publicadas no período.

Tabela 1 - Autores que mais publicaram sobre comércio justo no período

\begin{tabular}{cccccccc}
\hline Rank & Autores & Qtd & \% & Rank & Autores & Qtd. & \% \\
\hline \hline $1^{\mathbf{o}}$ & Becchetti, Leonardo. & 8 & 3,4 & $7^{\mathbf{0}}$ & Doran, Caroline J. & 3 & 1,3 \\
$2^{\mathbf{o}}$ & Davies, Iain. A. & 7 & 3,0 & $8^{\circ}$ & Barham, Bradford L. & 3 & 1,3 \\
$3^{\text {o }}$ & Ozcaglar-Toulouse, Nil & 4 & 1,7 & $9^{\mathbf{o}}$ & Bezencon, Valery & 3 & 1,3 \\
$4^{\mathbf{o}}$ & Beji-Becheur, Amina & 3 & 1,3 & $10^{\circ}$ & Blili, Sam & 3 & 1,3 \\
$5^{\circ}$ & Nicholls, Alexander J. & 3 & 1,3 & $11^{\circ}$ & Weber, Jeremy G. & 3 & 1,3 \\
$6^{\circ}$ & De Pelsmacker, Patrick & 3 & 1,3 & & Total de Trabalhos & 235 & 100 \\
\hline
\end{tabular}

Fonte: Elaborado pelos autores

No concernente à contagem de autores, evidenciou-se que as 235 publicações do período tiveram 427 pesquisadores diferentes, sendo, no total, 494 nos trabalhos. Este número remete a uma média de, aproximadamente, dois autores por artigo $(=2,10)$. Além disso, dentre os 427 diferentes, 381 publicaram somente um artigo no período $(=89,23 \%)$. Esta alta porcentagem de autores que produziram apenas um estudo no tema ressalta uma forte preocupação com o desenvolvimento de novas teorias dentro desta temática. Ou seja, como muitos autores não se dedicam a um estudo sistemático, a pesquisa não se aprofunda e as teorias não se desenvolvem.

Em seguida, na segunda etapa, foram analisados e tabulados os periódicos com mais publicações sobre comércio justo (tabela 2). Evidenciou-se que o Journal of Business Ethics lidera o ranking com uma presença que se destaca. Como 26,38\% (62) do total de trabalhos sobre o tema é publicado neste periódico, conclui-se que ele pode se caracterizar como a principal fonte de pesquisa sobre comércio justo. Demonstra-se, ainda, o grande espaço que os editores fornecem para o tema, possivelmente por acreditar em sua forte relevância e impacto social.

Tabela 2 - Periódicos com mais publicações sobre o tema

\begin{tabular}{ccccc}
\hline Rank. & Periódico & F. I.* & Qtd. & \% \\
\hline \hline $1^{\circ}$ & Journal of Business Ethics & 1,27 & 62 & 26,38 \\
$2^{\circ}$ & International Journal of Consumer Studies & 0,52 & 18 & 7,66 \\
$3^{\circ}$ & World Development & 1,53 & 12 & 5,11 \\
$4^{\circ}$ & Environment and Planning A & 1,63 & 10 & 4,26 \\
$5^{\circ}$ & Ecological Economics & 2,86 & 7 & 2,98 \\
\hline
\end{tabular}

Fonte: Elaborado pelos autores (*F.I. = Fator de Impacto).

Vale esclarecer, também, que a análise identificou que os 235 artigos foram publicados em 93 periódicos diferentes, sendo que 61 deles $(\sim 65,6 \%)$ só contaram com apenas uma publicação sobre o assunto. Isso demonstra a pouca quantidade de periódicos importantes e com espaço para a disseminação dos estudos sobre comércio justo.

A terceira fase da análise procurou compilar as nacionalidades dos autores principais de todos os 235 trabalhos pesquisados (tabela 3). Nesse sentido, os autores americanos aparecem liderando o ranking, com 54 trabalhos dentre os $235(\sim 23,0 \%)$, o que demonstra que o país representa o principal polo de pesquisa para esse tema. Além disso, cabe informar que foram encontrados, também, dois trabalhos onde o autor principal era brasileiro: Wilkinson (2011) e Cruz et al. (2007).

O artigo de Wilkinson (2011) propõe uma discussão sobre comércio justo e soja responsável no vantajoso contexto apresentado pelo Brasil enquanto o trabalho de Cruz et al. (2007) busca descrever o programa "Caras do Brasil", estudando suas principais características baseado em um modelo teórico de desenvolvimento sustentável exposto anteriormente. 
Tabela 3 - Países dos autores principais

\begin{tabular}{|c|c|c|c|c|c|c|c|}
\hline Rank & País Autor Principal & Qtd. & $\%$ & Rank & País Autor Principal & Qtd. & $\%$ \\
\hline $1^{\circ}$ & Estados Unidos & 54 & 23,0 & $16^{\circ}$ & Peru & 3 & 1,3 \\
\hline $2^{\circ}$ & Inglaterra & 34 & 14,5 & $17^{\circ}$ & Escócia & 3 & 1,3 \\
\hline $3^{\circ}$ & Canada & 20 & 8,5 & $18^{\circ}$ & Suécia & 3 & 1,3 \\
\hline $4^{\circ}$ & França & 18 & 7,7 & $19^{\circ}$ & País de Gales & 3 & 1,3 \\
\hline $5^{\circ}$ & Holanda & 15 & 6,4 & $20^{\circ}$ & Brasil & 2 & 0,9 \\
\hline $6^{\circ}$ & Itália & 11 & 4,7 & $21^{\circ}$ & África do Sul & 2 & 0,9 \\
\hline $7^{\circ}$ & Austrália & 10 & 4,3 & $22^{\circ}$ & Suíça & 2 & 0,9 \\
\hline $8^{\circ}$ & Bélgica & 7 & 3,0 & $23^{\circ}$ & Taiwan & 2 & 0,9 \\
\hline $9^{\circ}$ & Espanha & 7 & 3,0 & $24^{\circ}$ & China & 1 & 0,4 \\
\hline $10^{\circ}$ & Alemanha & 5 & 2,1 & $25^{\circ}$ & República Tcheca & 1 & 0,4 \\
\hline $11^{\circ}$ & Finlândia & 4 & 1,7 & $26^{\circ}$ & Índia & 1 & 0,4 \\
\hline $12^{\circ}$ & México & 4 & 1,7 & $27^{\circ}$ & Nova Zelândia & 1 & 0,4 \\
\hline $13^{\circ}$ & Noruega & 4 & 1,7 & $28^{\circ}$ & Nigéria & 1 & 0,4 \\
\hline $14^{\circ}$ & Dinamarca & 3 & 1,3 & $29^{\circ}$ & Polônia & 1 & 0,4 \\
\hline $15^{\circ}$ & Japão & 3 & 1,3 & Info & ação Não Disponível & 10 & 100 \\
\hline
\end{tabular}

Fonte: Elaborado pelos autores

$\mathrm{Na}$ quarta parte da análise, foram observados os trabalhos mais citados pelos 235 artigos, acerca de comércio justo, encontrados no período foco desta pesquisa (tabela 4). Assim, foram tabelados os 52 trabalhos que foram citados 12 vezes ou mais, sendo distribuídos na tabela 4 por ordem decrescente de frequência de citação. O artigo de Moore (2004) - The Fair Trade Movement: Parameters, Issues and Future Research - foi o trabalho que obteve o maior número de citações (42), estando, assim, presente em 17,9\% do total de trabalhos analisados na pesquisa.

Além disso, evidencia-se, também, a forte presença do Journal of Business Ethics e do periódico World Development na lista dos trabalhos mais relevantes para a construção e disseminação da teoria de comércio justo. Aponta-se, então, que estes dois periódicos não apresentam apenas uma alta quantidade de trabalhos sobre o tema, como, também, ressalta-se a qualidade e importância de suas publicações. Nesse sentido, cabe explorar, ainda, o fato de que, apesar do tema ser considerado bastante recente nas discussões acadêmicas, já há uma grande presença de livros (11) sobre o assunto entre os trabalhos mais citados.

Tabela 4 - Os 52 trabalhos mais citados de janeiro de 2001 a dezembro de 2013 sobre Comércio Justo

\begin{tabular}{|c|c|c|c|c|c|c|c|}
\hline Rank & Trabalhos & Qtd. & $\%$ & Rank & Trabalhos & Qtd. & $\%$ \\
\hline $1^{\circ}$ & $\begin{array}{c}\text { Moore, G. (2004) Journal of } \\
\text { Business Ethics }\end{array}$ & 42 & 17,9 & $27^{\circ}$ & $\begin{array}{c}\text { Strong, C. (1996) Marketing } \\
\text { Intelligence \& Planning }\end{array}$ & 16 & 6,6 \\
\hline $2^{\circ}$ & $\begin{array}{l}\text { Raynolds, L. T. et al. (2007) } \\
\text { - Fair Trade: Challenges }\end{array}$ & 40 & 17,0 & $28^{\circ}$ & $\begin{array}{c}\text { Auger, P. et al. (2003) Journal } \\
\text { of Business Ethics }\end{array}$ & 15 & 6,4 \\
\hline $3^{\circ}$ & $\begin{array}{l}\text { Pelsmacker, P. et al. (2005) } \\
\text { Journal Consumer Affairs }\end{array}$ & 37 & 15,7 & $29^{\circ}$ & $\begin{array}{c}\text { Doran, C. J. (2009) Journal of } \\
\text { Business Ethics }\end{array}$ & 15 & 6,4 \\
\hline $4^{\circ}$ & $\begin{array}{c}\text { Bacon, C. (2005) World } \\
\text { Development }\end{array}$ & 34 & 14,5 & $30^{\circ}$ & $\begin{array}{c}\text { Jaffee, D. et al. (2004) Rural } \\
\text { Sociology }\end{array}$ & 15 & 6,4 \\
\hline $5^{\circ}$ & $\begin{array}{c}\text { Renard, M.C. (2003) Journal } \\
\text { of Rural Studies }\end{array}$ & 33 & 14,0 & $31^{\circ}$ & $\begin{array}{c}\text { Ponte, S. (2002) World } \\
\text { Development }\end{array}$ & 15 & 6,4 \\
\hline $6^{\circ}$ & $\begin{array}{c}\text { Nicholls, A. J.; Opal, C. } \\
\text { (2005) - Fair Trade: Market }\end{array}$ & 32 & 13,6 & $32^{\circ}$ & $\begin{array}{l}\text { Shaw, D.; Clarke, I. (1999) } \\
\text { Marketing Intellig. \& Plan. }\end{array}$ & 15 & 6,4 \\
\hline $7^{\circ}$ & $\begin{array}{l}\text { Raynolds, L. T. (2002) } \\
\text { Sociologia Ruralis }\end{array}$ & 31 & 13,2 & $33^{\circ}$ & $\begin{array}{l}\text { Golding, K.; Peattie, K. (2005) } \\
\text { Sustainable Development }\end{array}$ & 14 & 6,0 \\
\hline $8^{\circ}$ & $\begin{array}{l}\text { Loureiro, M. L.; Lotade, J. } \\
\text { (2005) Ecolog. Economics }\end{array}$ & 29 & 12,3 & $34^{\circ}$ & $\begin{array}{c}\text { Leclair, M. S. (2002) World } \\
\text { Development }\end{array}$ & 14 & 6,0 \\
\hline $9^{\circ}$ & $\begin{array}{l}\text { Carrigan, M.; Attalla, A. } \\
\text { (2001) J.of Consumer Mark. }\end{array}$ & 27 & 11,5 & $35^{\circ}$ & $\begin{array}{c}\text { Low, W.; Davenport, E. } \\
\text { (2006) J. of Strategic } \\
\text { Marketing }\end{array}$ & 14 & 6,0 \\
\hline
\end{tabular}




\begin{tabular}{|c|c|c|c|c|c|c|c|}
\hline $10^{\circ}$ & $\begin{array}{c}\text { Raynolds, L. T (2000) } \\
\text { Agriculture and Human } \\
\text { Values }\end{array}$ & 25 & 10,6 & $36^{\circ}$ & $\begin{array}{l}\text { Maseland, R.; De Vaal, A. } \\
\text { (2002) De Economist }\end{array}$ & 14 & 6,0 \\
\hline $1^{\mathrm{o}}$ & $\begin{array}{c}\text { Taylor, P. L. (2005) World } \\
\text { Development }\end{array}$ & 24 & 10,2 & $37^{\circ}$ & $\begin{array}{c}\text { Moore, G. et al.(2006) } \\
\text { Journal of Strategic } \\
\text { Marketing }\end{array}$ & 14 & 6,0 \\
\hline po & $\begin{array}{l}\text { Raynolds, L. T. et al. (2004) } \\
\text { J. of Intern. Development }\end{array}$ & 23 & 9,8 & $38^{\circ}$ & $\begin{array}{l}\text { Murray, D. et al. (2003) - One } \\
\text { Cup at Time: Poverty }\end{array}$ & 14 & 6,0 \\
\hline $3^{\circ}$ & $\begin{array}{c}\text { Bird, K.; Hughes, D. R. } \\
\text { (1997) Business Ethics: } \\
\text { Euro. }\end{array}$ & 21 & 8,9 & $39^{\circ}$ & $\begin{array}{l}\text { Shaw, D; Shiu, E. (2003) } \\
\text { European Journal of } \\
\text { Marketing }\end{array}$ & 14 & 6,0 \\
\hline $14^{\circ}$ & $\begin{array}{l}\text { Jaffee, D. (2007) - Brewing } \\
\text { Justice: Fair Trade Coffee }\end{array}$ & 21 & 8,9 & $40^{\circ}$ & $\begin{array}{l}\text { Goodman, M. K. (2004) } \\
\text { Political Geography }\end{array}$ & 13 & 5,5 \\
\hline 50 & $\begin{array}{l}\text { Krier, J. M. (2001) - Fair } \\
\text { Trade in Europe } 2001\end{array}$ & 20 & 8,5 & $41^{\circ}$ & $\begin{array}{l}\text { Hudson, I.; Hudson, M. (2003) } \\
\text { Organization \& Environ. }\end{array}$ & 13 & 5,5 \\
\hline $16^{\circ}$ & $\begin{array}{l}\text { Low, W.; Davenport, E. } \\
\text { (2005) Sustainable Develop. }\end{array}$ & 0 & 8,5 & 42 & $\begin{array}{c}\text { Raynolds, L. T. (2009) World } \\
\text { Development }\end{array}$ & 13 & 5,5 \\
\hline $17^{\circ}$ & $\begin{array}{l}\text { Renard, M. C. (2005) } \\
\text { Journal of Rural Studies }\end{array}$ & 20 & 8,5 & $43^{\circ}$ & $\begin{array}{l}\text { Strong, C. (1997) Marketing } \\
\text { Intelligence \& Planning }\end{array}$ & 13 & 5,5 \\
\hline $18^{\circ}$ & $\begin{array}{l}\text { Nicholls, A. J. (2002) Int. J. } \\
\text { of Retail \& Distrib. Man. }\end{array}$ & 9 & 8,1 & 44 & $\begin{array}{c}\text { Arnot, C. et al. (2006) Can. J. } \\
\text { of Agricultural Economics }\end{array}$ & 12 & 5,1 \\
\hline $19^{\circ}$ & $\begin{array}{l}\text { Tallontire, A. (2000) } \\
\text { Development in Practice }\end{array}$ & 19 & 8,1 & $45^{\circ}$ & $\begin{array}{l}\text { Boulstridge, E.; Carrigan, M. } \\
\text { (2000) J.of Comm. Manag. }\end{array}$ & 12 & 5,1 \\
\hline $20^{\circ}$ & $\begin{array}{l}\text { Daviron, B.; Ponte, S. (2005) } \\
\text { - The Coffee Paradox }\end{array}$ & 17 & 7,2 & $46^{\circ}$ & $\begin{array}{c}\text { Gereffi, G. et al. (2005) } \\
\text { Review of Intern. Political } \\
\text { Econ. }\end{array}$ & 12 & 5,1 \\
\hline $21^{\circ}$ & $\begin{array}{l}\text { Hira, A.; Ferrie, J. (2006) } \\
\text { Journal of Business Ethics }\end{array}$ & 17 & 7,2 & $47^{\circ}$ & $\begin{array}{l}\text { Lyon, S. (2006) Internat. } \\
\text { Journal of Consumer Studies }\end{array}$ & 12 & 5,1 \\
\hline $22^{\circ}$ & $\begin{array}{l}\text { Davies, I. A.; Crane, A. } \\
\text { (2003) J. of Business Ethics }\end{array}$ & 16 & 6,8 & $48^{\circ}$ & $\begin{array}{c}\text { Micheletti, M. (2003)- } \\
\text { Political Virtue and Shopping }\end{array}$ & 12 & 5,1 \\
\hline $23^{\circ}$ & $\begin{array}{l}\text { Gereffi, G. (1994, p. 95) - } \\
\text { Global Commodity Chains }\end{array}$ & 16 & 6,8 & $49^{\circ}$ & $\begin{array}{l}\text { Raynolds, L.T et al. (2007) } \\
\text { Agriculture \& Human Values }\end{array}$ & 12 & 5,1 \\
\hline $24^{\circ}$ & $\begin{array}{l}\text { Littrell, M. A.; Dickson, M. } \\
\text { A (1999) - Social Respon. }\end{array}$ & 16 & 6,8 & $50^{\circ}$ & $\begin{array}{c}\text { Reed, D. (2009) Journal of } \\
\text { Business Ethics }\end{array}$ & 12 & 5,1 \\
\hline $25^{\circ}$ & $\begin{array}{l}\text { Low, W.; Davenport, E. } \\
\text { (2005) Int. Marketing Review }\end{array}$ & 16 & 6,8 & 51 & $\begin{array}{c}\text { Renard, M. C.; Perez-Grovas, } \\
\text { V. (2007) - Fair Trade }\end{array}$ & 12 & 5,1 \\
\hline $26^{\circ}$ & $\begin{array}{l}\text { Murray, D.L.; Raynold, L.T. } \\
\text { (2000) Agr. Human Val. }\end{array}$ & 16 & 6 & $52^{\circ}$ & $\begin{array}{c}\text { Waridel, L. (2002) - Coffee } \\
\text { with pleasure: Just Java }\end{array}$ & 12 & 5,1 \\
\hline
\end{tabular}

Fonte: Elaborado pelos autores

Por fim, na última fase da análise, foi construído um mapa de cocitações para os 32 trabalhos mais citados, segundo a análise anteriormente realizada (Figura 3). O valor encontrado para o nível normalizado de stress do modelo foi considerado adequado $(0,091)$. A partir disso, foram identificados quatro clusters principais, responsáveis por categorizar os trabalhos do tema, a saber: (1) grandes compilações teóricas sobre comércio justo, (2) implementação e certificação, (3) comportamento do consumidor e (4) Estratégia.

O primeiro cluster apresenta o maior número de citações, por se tratar de grandes compilações teóricas sobre Comércio Justo. Neste cluster, quatro trabalhos se destacam como principais, sendo dois livros e dois artigos. O artigo de Moore (2004) aborda o movimento do comércio justo, seus parâmetros, suas questões, além de motivar pesquisas futuras. O livro de Raynolds et al. (2007) é acerca dos desafios que esse movimento tem para ser uma ferramenta de transformação para globalização, no mercado tradicional. O artigo de Renard (2003) trata sobre esse tema analisando por três grandes tópicos: qualidade, mercado e convenções. O livro de Nicholls e Opal (2005) aborda o tema direcionando o leitor a uma análise do modo que o movimento de 
Comércio Justo pode estar sendo impulsionado pelo mercado de consumo ético, sob a perspectiva do consumidor. Assim, é possível perceber a importância destes quatro estudos, uma vez que é por meio deles que se torna possível observar como o Comércio Justo está conceituado e preconizado em âmbito global.

O segundo cluster é composto por estudos que se referem à implementação e certificação do Comércio Justo. Esses estudos são altamente relevantes para empresas/produtores que queiram se certificar, pois por meio deles torna-se possível conhecer como é esse processo de implementação, além de possibilitar a identificação dos desafios enfrentados até a certificação. No âmbito acadêmico, tem a relevância para o entendimento de como o Comércio Justo é visto na prática. $\mathrm{O}$ artigo do Bacon (2005), por exemplo, traz a reflexão da possibilidade de enfrentamento da crise do café, utilizando o Comércio Justo, orgânicos e cafés especiais para reduzir a vulnerabilidade do pequeno agricultor no norte da Nicarágua. Raynolds (2002) aborda em seu estudo ligações de consumidores e produtores em redes de café de Comércio Justo, ou seja, o autor já engloba o consumidor como um ponto relevante para o sucesso da cadeia produtiva. Taylor (2005) contribui trazendo a importância da certificação para o mercado, e questiona se as certificações de Comércio Justo e de Forest Stewardship Council (FSC) podem, de fato, provocar uma mudança social para o mercado atual. Esses três artigos são os mais citados desse cluster.

O terceiro cluster aborda o comportamento do consumidor em relação aos produtos de Comércio Justo. O estudo de Loureiro e Lotade (2005) mostram que consumidores estão dispostos a pagar prêmios mais elevados para café certificado de Comércio Justo. Esta descoberta pode ser utilizada por muitas organizações internacionais envolvidas na comercialização de produtos cultivados em países em desenvolvimento. Entretanto, os achados do estudo de Pelsmacker et al. (2005), com um número considerável de pesquisas, mostraram que os consumidores valorizam o aspecto ético em um produto. No entanto, o comportamento dos consumidores no mercado não é, aparentemente, de acordo com a sua atitude relatada para produtos com uma dimensão ética. Assim, o comportamento de compra dos consumidores não é coerente com a sua atitude positiva para produtos éticos. De uma forma, é possível perceber que é o consumidor quem desenvolve um papel ético de fato, ou seja, expressando isso no ato da compra que o movimento de comércio justo pode ganhar força e expansão em âmbito global.

O quarto cluster traz a discussão das estratégias de Comércio Justo. Nicholls (2002) traz em seus estudos a reflexão do motivo pelo qual o Comércio Justo não ganha a força que precisa ter para ser, de fato, um mercado que modifica a estrutura atual de comércio internacional. Ela ainda concluiu em seu estudo que uma estratégia junto ao consumidor necessita de uma consideração mais ampla, uma vez que está em processo de construção estratégica.

Além disso, a partir da visualização da figura 3 é possível perceber que o primeiro cluster é o que possui mais citações, visto que esse tema ainda está em processo de construção teórica. Por sua vez, o segundo cluster apresenta seus dados mais dispersos porque estes, em sua maioria, são estudos de casos mais específicos para o entendimento de uma determinada cadeia produtiva. $\mathrm{O}$ terceiro cluster possui três artigos interligados que, por sua vez, possuem muitas citações acerca do comportamento de compra dos consumidores. O quarto cluster apresenta artigos com poucas citações e bem dispersos. Por isso, este último cluster desperta um grande achado. É demonstrada, por meio de sua visualização, que a falta de uma estratégia consolidada para o tema de Comércio Justo pode ser o principal motivo pelo qual o tema não está disseminado, ainda, da forma apropriada para os consumidores e para acadêmicos. A estratégia é um ponto crucial para o movimento de Comércio Justo ganhar força e se tornar, de fato, uma ferramenta de mudança social. Ela deve ser voltada para os consumidores compreenderem o que, de fato, representa sua atitude de compra positiva para produtos provenientes de Comércio Justo. 


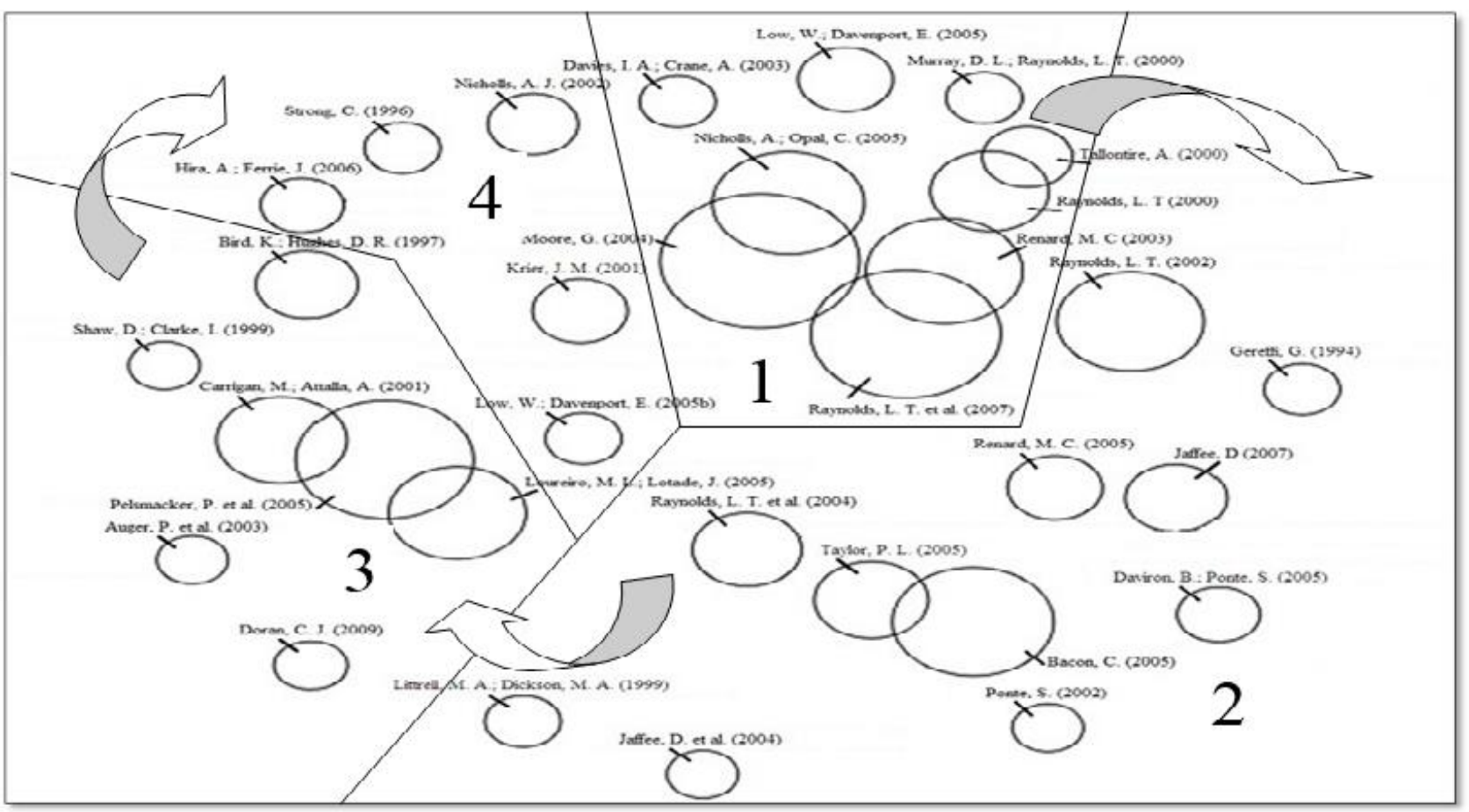

Figura 3-Mapa de cecitacõcs

Fonte: Elaborado pelos autores

Por fim, visualizando o mapa acima, cabe ressaltar ainda que estas classificações fornecidas pelos clusters e por toda a análise qualitativa dos artigos representam mais do que achados isolados dentro de cada um dos grupos. Dessa forma, eles representam uma proposta de configuração e estruturação das pesquisas sobre o tema. Neste novo modelo, as pesquisas estariam enquadradas em quatro etapas do sistema, representando um ciclo das fases que compõem o processo. Ou seja, relacionando-se também com a figura 1 - "o sistema de comércio justo", as compilações teóricas levariam a implementação e certificação, caminhando, em seguida, para o consumidor e proporcionariam, então, novas estratégias para seu processo. Por fim, o ciclo é reiniciado. Este modelo de estruturação e classificação das pesquisas na área é mostrado abaixo, na figura 4:

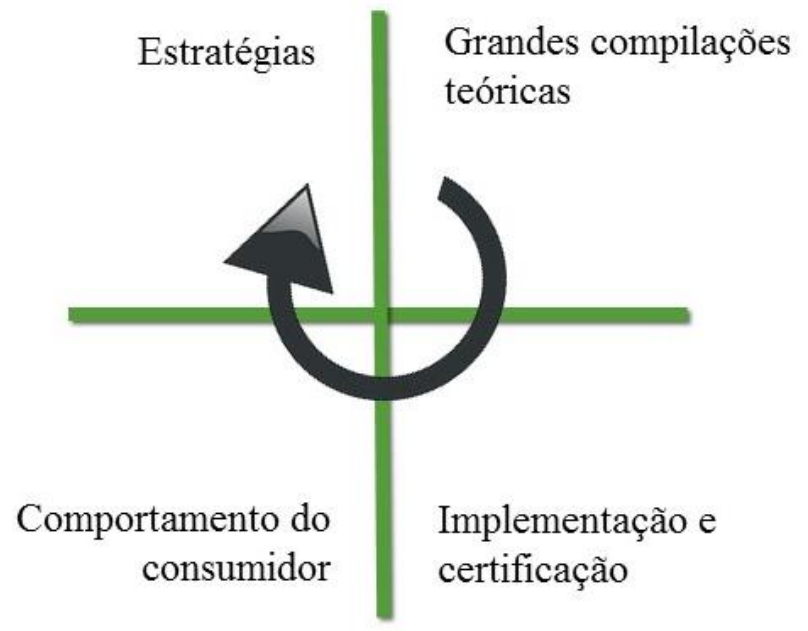

Figura 4 - Modelo de estruturação e classificação de pesquisas sobre comércio justo Fonte: Elaborado pelos autores 
Por outro lado, apesar de se acreditar na validade do modelo, nossa análise revelou que o cenário atual das pesquisas remonta a determinadas quebras sistemáticas neste ciclo e nestas ligações entre as etapas. Isto ocorre, principalmente, devido à deficiência de comunicação entre as fases do sistema de Comércio Justo. Nesse sentido, uma potencial sugestão para o desenvolvimento do campo de estudo seria a elaboração de trabalhos que interconectem estas etapas do modelo.

\section{DISCUSSÃO DOS RESULTADOS E CONCLUSÃO}

Como a quantidade de informações encontradas internacionalmente sobre Comércio Justo é bastante significativa (Sebrae, 2007), buscou-se, por meio dessa pesquisa, analisar e organizar os estudos relacionados ao assunto para uma melhor visualização de seu estado-da-arte. Visando a esse fim, uma pesquisa bibliométrica foi conduzida, avaliando todos os artigos publicados de 2001 a 2013 sobre o tema e indexados na base Web of Science.

Inicialmente, foi visto que quase $90 \%$ do total de pesquisadores com publicações sobre comércio justo possuem somente um único estudo. Este fato pode ser um problema potencial para o futuro das pesquisas neste campo, uma vez que não há pesquisadores sistemáticos, que desenvolvam seus estudos em cima das lacunas latentes na literatura e de seus próprios achados. Outra discussão é referente à análise dos periódicos com maior número de publicações sobre o tema. Acerca disto, foi descoberto que o Journal of Business Ethics é um importante locus para a disseminação do tema, sendo o principal dos poucos periódicos que tem incentivado as pesquisas no campo por meio do espaço dado a elas. Apenas 32 dos periódicos indexados na Web of Science possuem mais de um artigo sobre o assunto.

No concernente ao país de filiação dos autores principais dos estudos, a análise evidenciou que os Estados Unidos representam o principal polo de pesquisa sobre Comércio Justo. Coube, ainda, ressaltar a contribuição de dois trabalhos que possuem acadêmicos de universidades brasileiras como autores principais (Wilkinson, 2011; Cruz et al., 2007). Outro resultado, obtido por meio da análise de citações, é a lista dos 52 trabalhos mais relevantes para o desenvolvimento de pesquisas na área. Foi visto que, além da grande presença de livros, os artigos, em geral, pertenciam aos mesmos periódicos que mais continham publicações, elucidando, também, a relevância destes repositórios científicos.

Por fim, a análise do mapa de cocitações culminou na descoberta de uma forma de estruturação das pesquisas do tema. Essa estrutura possui quatro etapas, a saber: (1) definição e discussões abrangentes do movimento de Comércio Justo; (2) entendimento do processo de implementação e certificação; (3) perspectiva do consumidor e (4) estratégia para disseminação do comércio Justo. Nesse sentido, além de apresentar os principais trabalhos presentes em cada um dos clusters, sugere que as pesquisas podem ser categorizadas e tratadas como etapas de um processo que deve ser, então, entendido e aperfeiçoado em todas estas fases. Ademais, o mapa representa, apropriadamente, a maneira como o tema evoluiu ao longo dos anos. Assim, compreende-se que o Comércio Justo iniciou-se com uma devida discussão epistemológica, atribuindo conceitos e escopos, passando, em seguida, por uma estruturação de sua cadeia e processo. Após esta fase, o olhar se voltou para o consumidor, buscando-se entender o papel a ele atribuído neste processo. Por fim, entra em foco a proposição de estratégias e planos de ação para a disseminação e proposição de uma predisposição por parte dos consumidores com o Comércio Justo.

Tendo isso em vista, o principal achado deste estudo aponta que a maior lacuna encontrada nos trabalhos se reflete na dificuldade de aderência por parte do consumidor em exercer uma atitude positiva na compra de um produto de Comércio Justo. Nesse sentido, recomenda-se desenvolver, por meio de novas pesquisas, estratégias mais claras de comunicação acerca do que é o Comércio Justo, com foco para os consumidores. O tema de Comércio Justo está em fase de construção teórica e nos últimos anos vem ganhando força, entretanto esse estudo aponta que há um longo caminho a ser percorrido no que tange as estratégias voltadas para os consumidores. Além disso, 
com base nos resultados, pode-se afirmar que o este estudo contribui consistentemente para a literatura, não só organizando estudos sobre Comércio Justo, como também oferecendo orientações relevantes para pesquisas futuras. Contribui, ainda, ao propor uma forma de visualização dos trabalhos, por meio de suas categorizações, que melhor auxiliarão no entendimento do tema e construção consistente de linhas de estudo. Portanto, em suma, uma potencial contribuição do artigo reside na demonstração do estado-da-arte de estudos internacionais sobre o assunto a leitores brasileiros, buscando, dessa forma, estimular estes acadêmicos a realização de novas pesquisas.

Por outro lado, este estudo possui limitações que devem ser observadas. Em primeiro lugar, há uma limitação referente ao escopo temporal utilizado. Como as discussões sobre esse tema são datadas desde meados do século passado e este estudo analisou somente artigos publicados de 2001 a 2013, é possível que, se houvesse uma maior abrangência temporal, alguns destes achados se modificassem. Contudo, esta decisão foi tomada pelos pesquisadores com o intuito de visualizar, essencialmente, os estudos mais recentes, favorecendo, assim, uma orientação mais efetiva para os futuros trabalhos. Sabendo disso, seria indicado na elaboração de novas pesquisas que houvesse a ampliação deste escopo.

Uma limitação que vale ser notada diz respeito à escolha da base de dados. Apesar de ter sido tomada a decisão de apenas focar nos artigos indexados na Web of Science, adotada por ser a principal para as ciências sociais (Capes, 2010), cabe ressaltar que outras bases, apresentam, indubitavelmente, resultados igualmente válidos e relevantes. Portanto, sabendo que os resultados ficaram limitados a análise somente desta fonte, seria interessante a realização de novos estudos que se utilizem de outras bases ou que, até mesmo, trabalhem, concomitantemente, com várias delas. Além disso, há, por fim, uma limitação concernente a forma com que os dados foram analisados. Como se utilizou um software especializado em análises bibliométricas para absorver informações de uma grande quantidade de publicações, tornou-se inviável uma verificação qualitativa de toda a amostra. Assim, este estudo se limitou a investigar o conteúdo somente dos artigos com maior número de citações. Ademais, o objetivo deste tipo de trabalho fica limitado a proporcionar uma abrangente avaliação sobre a estruturação e macrotendências deste tópico, atentando-se para o direcionamento dos trabalhos e como eles se enquadram e se representam no panorama geral deste campo. Portanto, o recomendável, neste primeiro momento, seria primar por uma visualização holística do tema, para, posteriormente, tratar com um olhar mais atento e detalhado informações mais específicas. Nesse sentido, para futuras pesquisas, sugere-se a realização de uma revisão da literatura que trate, de modo qualitativo, os dados em seus conteúdos, compreendendo profundamente as principais contribuições de cada um dos estudos contidos na amostra e, ainda, em cada uma das categorias que emergiram da análise dos resultados.

\section{REFERÊNCIAS}

Arnot, C., Boxall, P. C. \& Cash, S. B. (2006) Do ethical consumers care about price? A revealed preference analysis of fair trade coffee purchases. Canadian Journal of Agricultural Economics, 54(4), 555-565.

Asti, A. L. (2007) Comércio justo e o caso do algodão: a cadeia produtiva têxtil brasileira. Dissertação de Mestrado não publicada, UFRRJ, Rio de Janeiro, Brasil.

Auger, P., Burke, P., Devinney, T. M. \& Louviere, J. J. (2003) What will consumers pay for social product features? Journal of Business Ethics, 42(3), 281-304.

Bacon, C. (2005) Confronting the coffee crisis: can fair trade, organic, and specialty coffees reduce small-scale farmer vulnerability in northern Nicaragua? World Development 33(3), 497-511.

Bird, K. \& Hughes, D. R. (1997) Ethical consumerism: the case of "fairly-traded" coffee. Business Ethics: A European Review 6(3), 159-67. 
Boulstridge, E. \& Carrigan, M. (2000) Do consumers really care about corporate responsibility? Highlighting the attitude-behavior gap. Journal of Communication Management, 4(4), 355-368.

Brasil Social Chic (2014) Recuperado em 17 de março de 2014, de $<$ http://brasilsocialchic.com/v01/>

Capes (2010) Portal brasileiro da informação científica. Recuperado em 01 de Fevereiro de 2014, de <http://www2.periodicos.capes.gov.br/portugues/index.jsp?urlorigem=true>. Carrigan, M. \& Attalla, A. (2001) The myth of the ethical consumer-Do ethics matter in purchase behavior? Journal of Consumer Marketing, 18(7), 560-577.

Cherrier, H. (2007) Ethical consumption practices: co-production of self-expression and social recognition. Journal of Consumer Behaviour 6(5), 321-335.

Crossing Borders Fair Trade (2014) Recuperado em 25 de março de 2014, de <http://www.crossing-borders-fair-trade.com/network-of-european-worldshops.html>.

Cruz, L. B., Pedrozo, E. A., Bacima, R. \& Queiroz, B. (2007) Company and society - The "Caras do Brasil" (Faces of Brazil) program as leverage for sustainable development. Management Decision, 45(8), 1297-1319.

Davies, I. \& A. Crane (2003) Ethical decision making in fair trade companies, Journal of Business Ethics, 45, 79-92.

Daviron, B. \& Ponte, S. (2005) The coffee paradox: commodity trade and the elusive promise of development. London, UK: Zed Books.

Doane, D. (2001) Taking flight: the rapid growth of ethical consumerism. London: New Economics Foundation.

Doran, C. J. (2009) The role of personal values in fair trade consumption. Journal of Business Ethics, 84, 549-563.

Faces do Brasil (2014) Comércio Justo no Brasil. Recuperado em 25 de março de 2014, em <http://www.facesdobrasil.org.br/comercio-justo-no-brasil.html>.

Fine (2005) Facts and figures on fair trade in 25 european countries. Recuperado em 25 de Novembro de 2014, em <http://www.fbes.org.br/>.

Gereffi, G. (1994) The organization of buyer-driven global commodity chains: how US retailers shape overseas production networks. In G. Gereffi and M. Korzeniewicz (eds.), Commodity chains and global capitalism (Praeger, Westport, Conn), 95-122.

Gereffi, G., Humphrey, J., \& Sturgeon, T. (2005) The governance of global value chains. Review of International Political Economy, 12(1), 78-104.

Golding, K. \& K. Peattie (2005) In search of a golden blend: perspectives on the marketing fair trade coffee. Sustainable Development, 13, 154-65.

Goodman, M. K. (2004) Reading fair trade: political ecological imaginary and the moral economy of fair trade foods. Political Geography, 23, 891-915.

Hira, A. \& Ferrie, J. (2006) Fair trade: three key challenges for reaching the mainstream. Journal of Business Ethics, 63, 107-118

Hudson, I. \& Hudson, M. (2003) Removing the veil? Commodity fetishism, fair trade and the environment. Organisation and Environment, 16(4), 413-430.

Jaffee, D., J. R. Kloppenburg, JR. \& M. B. Monroy (2004) Bringing “the moral charge"' home: fair trade within the north and within the south, Rural Sociology, 69(2), 169-196. 
Jaffee D. (2007) Brewing justice: fair trade coffee, sustainability, and survival. University of California Press: Berkeley.

Krier, J. M. (2001) Fair trade in Europe 2001: facts and figures on the fair trade sector in 18 european countries. Maastricht: EFTA Research Report.

Leclair, M. S. (2002) Fighting the tide: alternative trade organizations in the era of global free trade, World Development. 30(6), 949-958.

Littrell, M. A. \& M. A. Dickson (1999) Social responsibility in the global market: fair trade of cultural products (Sage, Thousand Oaks).

Loureiro, M. L. \& J. Lotade (2005) Do fair trade and eco-labeling in coffee wake up the consumer conscience? Ecological Economics 53: 129-38.

Low, W. \& E. Davenport (2005) Postcards from the edge: maintaining the "alternative'” character of fair trade. Sustainable Development, 13(3), 143-153.

Low, W., \& Davenport, E. (2005) Has the medium (roast) become the message?. International Marketing Review, 22(5), 494-511.

Low, W., \& Davenport, E. (2006) Mainstreaming fair trade: adoption, assimilation, appropriation. Journal of Strategic Marketing, 14, 315-327.

Lyon, S. (2006) Evaluating fair trade consumption: politics, defetishization and producer participation. International Journal of Consumer Studies, 30, 452-464.

Maseland, R. \& A. De Vaal (2002) How fair is fair trade. De Economist, 150(3), 251-272.

Mielants, C., Pelsmacker, P. \& Janssens, W. (2003) Kennis, houding en gedrag van de belgen t.a.v. fair trade producten. conclusies uit vier focusgroepgesprekken. UAMS research paper. Antwerpen, Belgium: Universiteit Antwerpen Management School.

Micheletti, M. (2003) Political virtue and shopping: individuals, consumerism and collective action. Palgrave Macmillan, New York.

Moore, G. (2004) The fair trade movement: parameters, issues, and future research. Journal of Business Ethics, 53, 73-86.

Moore, G., Gibbon, J., \& Slack, R. (2006) The mainstreaming of fair trade: a macromarketing perspective. Journal of Strategic Marketing, 14, 329-352.

Murray, D. L. \& L. T. Raynolds (2000) Alternative trade in Bananas: obstacles and opportunities for progressive social change in the global economy. Agriculture and Human Values, 17, 65-74.

Murray, D., Raynolds, L. T. \& Taylor, P. (2003) One cup at a time: poverty alleviation and fair trade coffee in Latin America. Fort Collins, Colorado: Colorado State University.

Newholm, T. \& Shaw, D. (2007) Studying the ethical consumer: a review of research. Journal of Consumer Behaviour, 6, 253-270.

Nicholls, A. J. (2002) Strategic options in fair trade retailing. International Journal of Retail and Distribution Management, 30(1), 6-17.

Nicholls, A., Opal, C. (2005) Fair trade: market driven ethical consumption, Sage, London.

Pelsmacker, P., Driesen, L. \& Rayp, G. (2005) Do consumers care about ethics? Willingness to pay for fair-trade coffee. Journal of Consumer Affairs 39, 363-85.

Ponte, S. (2002) The 'latte revolution? Regulation, markets and consumption in the global coffee chain'. World Development, 30(7), 1099-1122. 
Raynolds, L. T. (2000) Re-embedding global agriculture: the international organic and fair trade movements. Agriculture and Human Values, 17, 297-309.

Raynolds, L. T. (2002) Consumer/producer links in fair trade coffee networks. Sociologia Ruralis, 42(4), 404-424.

Raynolds, L. T., D. Murray, \& P. L. Taylor (2004) Fair trade coffee: building producer capacity via global networks. Journal of International Development, 16(8), 1109-1121.

Raynolds, L., Murray, D., \& Heller, A. (2007) Regulating sustainability in the coffee sector: a comparative analysis of third-party environmental and social certification initiatives. Agriculture and Human Values, 24(2), 147-163.

Raynolds, L. T., D. Murray And J. Wilkinson (2007) Fair trade: the challenges of transforming globalization (Routledge, London and New York), pp. 223-234.

Raynolds, L. T. (2009) Mainstreaming fair trade coffee: from partnership to traceability. World Development, 37, 1083-1093.

Reed, D. (2009) What do corporations have to do with fair trade? Positive and normative analysis from a value chain perspective. Journal of Business Ethics, 86, 3-26.

Renard M.-C., (2003) Fair trade: quality, markets and conventions. Journal of Rural Studies, 19, 87-96.

Renard, M. C. (2005) Quality certification, regulation and power in fair trade. Journal of Rural Studies, 21(4), 419-431.

Roberts, J. A. (1996) Will the real socially responsible consumer please step forward? Business Horizons, 39 (1), 79-83.

Sebrae (2007) Comércio justo e solidário: pesquisa mundial de comércio Justo - versão 2007. Recuperado em 13 de março de 2014, de: <http://www2.ba.sebrae.com.br/banco/documentos/biblioteca/comercio\%20justo.pdf>.

Shaw, D. \& Clarke, I. (1999) Belief formation in ethical consumer groups: an exploratory study. Marketing Intelligence \& Planning, 17 (2/3), 109-119.

Shaw, D. \& Shiu, E. (2003) Ethics in consumer choice: a multivariate modelling approach. European Journal of Marketing, 10, 1485-1498.

Strong, C. (1996) Features contributing to the growth of ethical consumerism-A Preliminary Investigation. Marketing Intelligence \& Planning, 14 (5), 5-13.

Strong, C., (1997) The problem of translating fair trade principles into consumer purchase behaviour. Marketing Intelligence and Planning, 15(1), 32-37.

Tallontire, A. (2000) Partnerships in fair trade: reflections from a case study of cafe'direct. Development in Practice, 10(2), 166-177.

Taylor, P. L. (2005) In the market but not of it: fair trade coffee and forest stewardship council certification as market-based social change. World Development, 33(1), 129-147.

Waridel, L. (2002) Coffee with pleasure: just java and world trade (Black Rose, Montréal).

Wfto (2014) Recuperado em 25 de março de 2014, de <http://www.wfto.com/index.php?option=com_content\&task =view\&id=889\&Itemid=290>.

White, D., Mccain, K. (1998) Visualizing a discipline: an author co-citation analysis of information science, 1972-1995. Journal of the American Society for Information Science, vol. 49, pp. 327-355. 
Wilkinson, J. (2011) From fair trade to responsible soy: social movements and the qualification of agrofood markets. Environment and Planning A, 43(9), 2012-2026.

Data da submissão: 03/06/2015

Data da publicação: 30/04/2016 